\title{
The Use and Performance of Wrought 625 Alloy in Primary Surface Recuperators for Gas Turbine Engines
}

\author{
James M. Rakowski ${ }^{1}$, Charles P. Stinner ${ }^{1}$, Mark Lipschutz ${ }^{2}$, J. Preston Montague ${ }^{2}$ \\ ${ }^{1}$ ATI Allegheny Ludlum, an Allegheny Technologies company \\ Technical and Commercial Center, 1300 Pacific Avenue, Brackenridge, PA, 15014, USA \\ ${ }^{2}$ Solar Turbines Incorporated \\ 2200 Pacific Highway, San Diego, CA, 9286, USA
}

Keywords: Oxidation, Recuperator, Volatility, Water Vapor

\begin{abstract}
Recuperation increases the efficiency of a gas turbine engine by extracting heat from the exhaust gas stream and using it to pre-heat the compressor discharge air. High temperature oxidation and creep are major concerns, necessitating the use of heat-resistant alloys for the recuperator panels. Most current recuperator designs specify austenitic stainless steel foil as the material of construction. Water vapor, present in the exhaust gas as a by-product of combustion, has been shown to be detrimental to elevated temperature oxidation resistance, particularly for ferrous alloys. The protective chromium oxide scale breaks down rapidly in the presence of water vapor due to the formation of fast-growing iron oxide nodules. Increasing the amount of chromium and nickel appears to alleviate the risk of breakaway oxidation. Alloy 625, a common wrought $\mathrm{Ni}-\mathrm{Cr}-\mathrm{Mo}$ superalloy, is a candidate material for recuperator air cells. Long-term oxidation testing of 100 micron thick samples performed at $704-815^{\circ} \mathrm{C}\left(1300-1500^{\circ} \mathrm{F}\right)$ did not result in breakaway oxidation but indicated a tendency towards weight loss. The observed oxidation kinetics can be explained by a model combining the simultaneous growth and evaporation of an oxide layer. Evaporation of chromia appears to be accelerated in the presence of water vapor by the formation of volatile species such as chromium oxyhydroxide. Comparing these results to those of other nickel-base superalloys and high-alloy content stainless steels revealed that minor element chemistry can be modified to mitigate evaporation by the formation of an external spinel oxide layer.
\end{abstract}

\section{Introduction}

Recuperation is a means for increasing the efficiency of a simple-cycle gas turbine. A primary surface recuperator allows for heat transfer between the turbine exhaust and compressor discharge gas streams in a gas turbine in a highly efficient, relatively compact package. This serves to increase the temperature of the air entering the combustor, effectively decreasing the amount of fuel required to reach the desired turbine inlet temperature. Figure 1 illustrates a recuperated cycle in schematic form. 


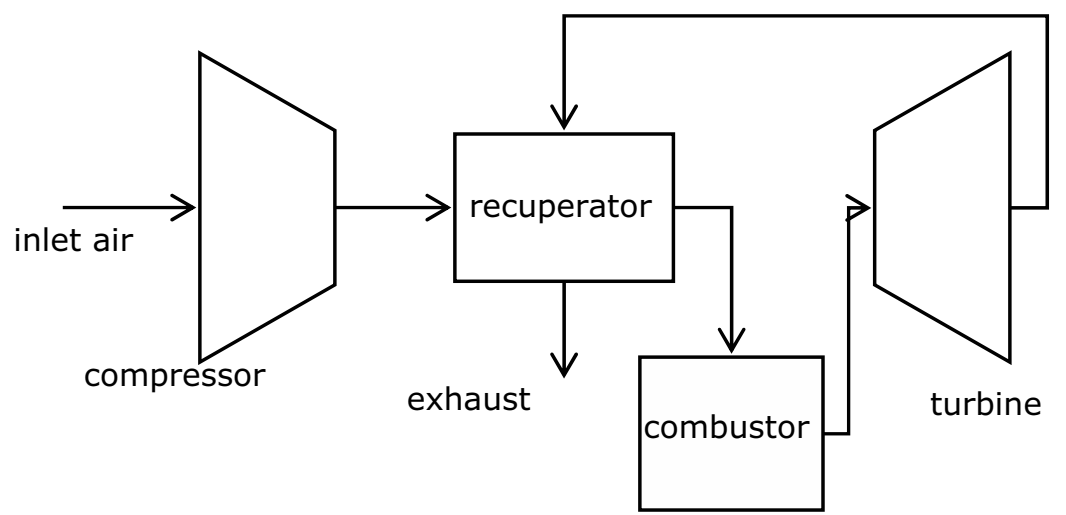

Figure 1: Schematic flow path for a recuperated gas turbine cycle

Figure 2 presents varying levels of detail of a design for one type of primary surface recuperator (specifically, the unit used on Solar Turbines' Mercury 50 engine). The basic repeat unit of this design is the air cell, which consists of two distinct plates which are formed out of sheets of thin (100 microns) heat-resistant metallic alloys by a fin-folding process. The two plates are edge welded together into a unit. The air cells are then stacked into a recuperator core of desired length, which is held together by tensioning rods and encased in ductwork.
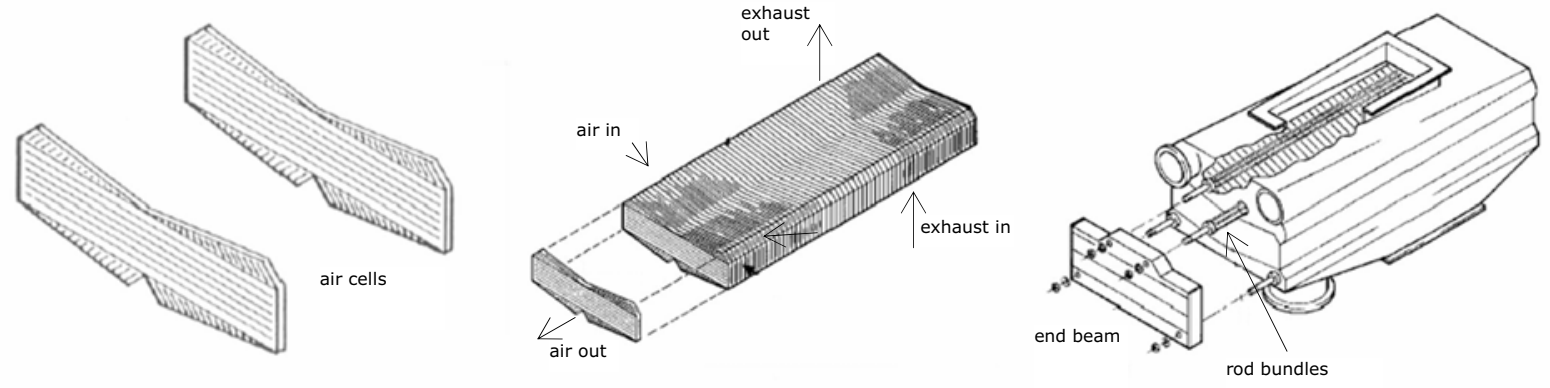

Figure 2: Schematic of Mercury 50 gas turbine recuperator at various levels of detail

The primary surface recuperator design presents several challenges for materials selection. Among these is failure due to high-temperature oxidation in the gas turbine exhaust stream environment. Water vapor is encountered as a minor component in ambient air and in larger concentrations as a by-product of various industrial processes such as combustion. It has been known for some time that the presence of water vapor in oxidizing environments can alter the degradation process for many different metals [1]. When present in oxygen-bearing atmospheres or as the primary oxidant, water vapor appears to hasten the onset of rapid oxidation of $\mathrm{Fe}-\mathrm{Cr}$ and Fe-Cr-Ni alloys at elevated temperatures [2-30]. The results vary from study to study, but water vapor tends to accelerate the rate of oxidation, leads to the formation of layered scales, and increases the amount of chromium required to form a protective oxide film. Work focused specifically on Fe-Cr-Ni alloys suggests that higher chromium and nickel contents (or conversely, a low iron content) increase oxidation resistance in environments containing water vapor [24-33]. Studies involving austenitic stainless steels noted that a thin chromium oxide layer is established on the sample surface during initial exposure to air containing water vapor. The amount of chromium incorporated into this scale is not large enough to result in significant depletion of the underlying metal. Therefore, the occurrence of breakaway oxidation in this case should not be due solely to the expected chromium depletion of the substrate. Rapid weight gain occurs due to the formation and growth of mixed oxide nodules. These nucleate at isolated locations after an incubation time and then spread, consuming the initially-formed protective oxide layer. This observation is supported by the fact that remnants of the initial chromium oxide layer survive on heavily degraded samples $[19,20]$. It is unclear if the nodules form as a direct 
result of the action of water vapor (or hydrogen), or if water vapor plays a role in inhibiting healing of flaws, cracks, and spalled regions by the formation of new chromium oxide. Alternatively, the water vapor may be enhancing chromium depletion due to oxide scale evaporation, leading to early breakaway [34,35].

The damaging effect of water vapor on low-alloy content stainless steels has led to the substitution of higher-alloy materials, such nickel-base superalloys, in applications where oxidation failure is a concern. The effect of water vapor is manifested in other forms than simple breakaway oxidation for such materials. One common effect that becomes apparent for chromiaforming materials that do not enter breakaway oxidation is oxide scale evaporation [36]. Chromium oxide volatilizes in the absence of water vapor as higher chromium oxides, an effect most pronounced at temperatures above approximately $1000^{\circ} \mathrm{C}\left(1832^{\circ} \mathrm{F}\right)$ [22]. The chromium trioxide species has the highest vapor pressure in this situation (Equation 1).

$$
2 \mathrm{Cr}_{2} \mathrm{O}_{3(\mathrm{~s})}+3 \mathrm{O}_{2(\mathrm{~g})}=4 \mathrm{CrO}_{3(\mathrm{~g})}
$$

Water vapor can increase the evaporative flux of chromium-bearing volatile species to levels where it is significant at much lower temperatures. This is due to the formation of volatile oxyhydroxides of chromium, as in Equation 2 [23-25].

$$
2 \mathrm{Cr}_{2} \mathrm{O}_{3(\mathrm{~s})}+3 \mathrm{O}_{2(\mathrm{~g})}+4 \mathrm{H}_{2} \mathrm{O}_{(\mathrm{g})}=4 \mathrm{CrO}_{2}(\mathrm{OH})_{2(\mathrm{~g})}
$$

Figure 3 compares the calculated partial pressures for different chromium-bearing vapor species in equilibrium with air containing water vapor. The primary species of concern is $\mathrm{CrO}_{2}(\mathrm{OH})_{2}$, which has a vapor pressure several orders of magnitude higher than that expected for $\mathrm{CrO}_{3}$ when water vapor is present in the gas. Furthermore, the oxy-hydroxide vapor pressure is relatively insensitive to temperature, which serves to magnify the difference at the lower temperatures $\left(600-750^{\circ} \mathrm{C}\right)$ typical of recuperator operation $[8,37]$.

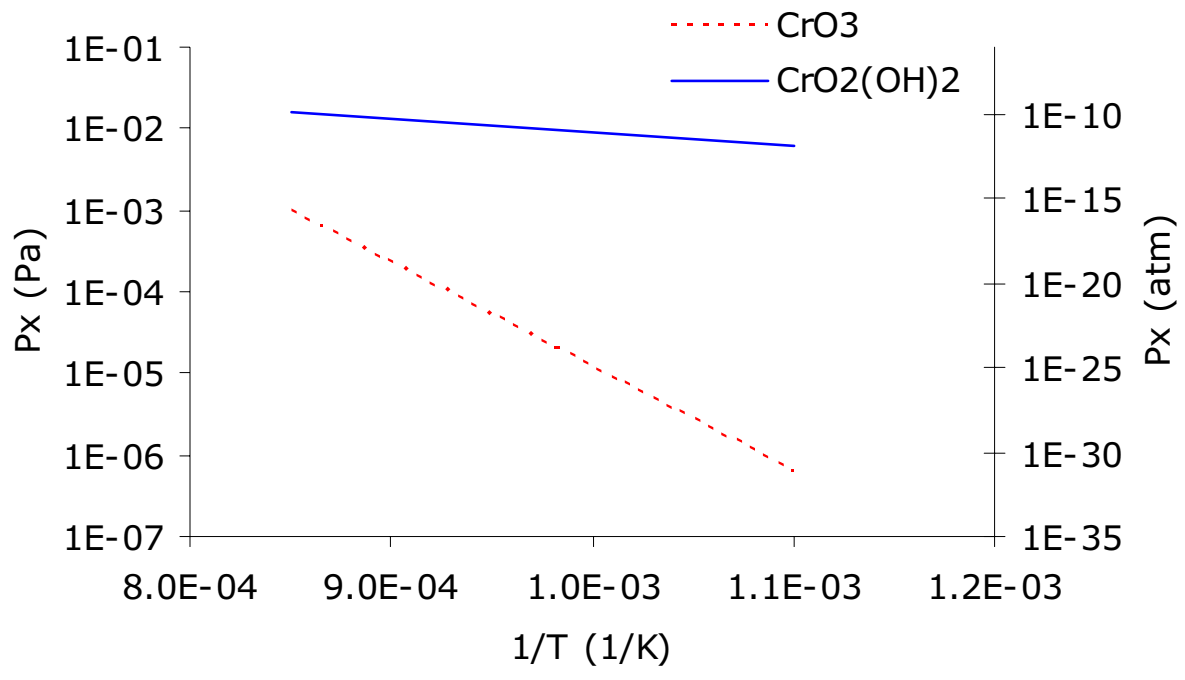

Figure 3: Vapor pressures of various volatile species for chromium oxide in equilibrium with air containing approximately $2 \%$ water vapor by volume

Oxide scale evaporation can result in the significant loss of chromium from metallic substrates to the surrounding environment, particularly in rapidly-flowing gas streams. High flow rates sweep the vapor species away from the immediate region of the gas-solid interface, promoting further evaporation in an attempt to maintain thermodynamic equilibrium between the species in the gas 
and condensed phases. These species are then free to react with their surroundings. This paper gives results and analysis from extended high-temperature oxidation testing of the wrought nickel-base superalloy 625 in air with and without added levels of water vapor. Comparative results are presented for a different wrought nickel-base superalloy (HX alloy) and an experimental austenitic stainless steel to provide insight into the effect of compositional variations. Conclusions relevant to the use of such materials in water vapor-bearing environments are provided.

\section{Experimental Procedure}

The test samples for this study were prepared from a single sheet of $0.10 \mathrm{~mm}$ thick 625 alloy foil (composition as specified in UNS N06626), taken from a coil produced by ATI Allegheny Ludlum. This material was produced by a double melt process and meets the specification requirements for both AMS 5599 and AMS 5879. The initial step was vacuum induction melting, followed by homogenization via electroslag remelting. Similar samples of another highly alloyed wrought superalloy, HX alloy (composition specified in UNS N06002), and an experimental austenitic stainless steel were used for comparative studies. The compositions of all of the samples were determined by an in-house certified production laboratory using standard analytical chemistry techniques and are detailed in Table I.

Table I. Test Sample Chemistries (Weight Percent)

\begin{tabular}{|ccccccccccc|}
\hline & $\mathrm{Cr}$ & $\mathrm{Fe}$ & $\mathrm{Mo}$ & $\mathrm{Nb}$ & $\mathrm{Si}$ & $\mathrm{Al}$ & $\mathrm{Ti}$ & $\mathrm{Mn}$ & $\mathrm{Ni}$ & Other \\
\hline $\begin{array}{c}\text { 625 alloy } \\
\text { (UNS N06626) }\end{array}$ & 20.8 & 4.4 & 8.3 & 3.8 & 0.13 & 0.21 & 0.17 & 0.03 & bal. & \\
\hline $\begin{array}{c}\text { HX alloy } \\
\text { (UNS N06002) }\end{array}$ & 22.8 & 18.8 & 9.0 & 0.08 & & & & 0.60 & bal. & $\begin{array}{c}1.13 \mathrm{Co} \\
0.49 \mathrm{~W}\end{array}$ \\
\hline $\begin{array}{c}\text { AL 20-25+Nb } \\
\text { alloy }\end{array}$ & 21.0 & bal. & 1.5 & 0.34 & 0.47 & 0.16 & 0.02 & 0.99 & 26.0 & $0.10 \mathrm{~N}$ \\
\hline
\end{tabular}

TM Trademark of ATI Properties, Inc.

The material as-tested was bright annealed in hydrogen after cold rolling with smooth rolls (commercially referred to as a 2BA finish). Oxidation testing was carried out in both ambient laboratory air and in air with added water vapor. The ambient air oxidation testing was conducted to provide baseline data for the humidified air testing. These exposures were performed in box furnaces where air flow was by natural convection. The samples were held in tall alumina crucibles. The water vapor content of the climate-controlled laboratory air is approximately $0.5 \%$ by volume year-round, based on measurements of relative humidity and temperature. The humidified air exposures were carried out in tube furnaces incorporating three inch diameter, gas-tight tubular retorts. The air flow velocity was approximately $0.004 \mathrm{ft} / \mathrm{s}$ $(0.0012 \mathrm{~m} / \mathrm{s})$ at an overpressure of $4 \mathrm{psi}(6.9 \mathrm{kPa})$, as supplied from a standard gas bottle and regulator. Samples were held in egg-crate boats to promote exposure to the flowing gas. Water vapor was added by first passing the flowing air through a fritted glass disk immersed in a flask of distilled water held at a temperature of approximately $80^{\circ} \mathrm{C}\left(176^{\circ} \mathrm{F}\right)$. The humidified gas stream was then passed through a second flask held in a constant temperature bath at either $39^{\circ} \mathrm{C}$ $\left(102^{\circ} \mathrm{F}\right)$ or $46^{\circ} \mathrm{C}\left(115^{\circ} \mathrm{F}\right)$, corresponding to water vapor contents of $7 \%$ and $10 \%$ by volume, respectively. The samples were thermally cycled to room temperature once per week (approximately every 160 hours) for weighing and visual examination in both the ambient and humidified air tests. 
Oxidation Test Results - Ambient Air

Oxidation testing of 625 alloy foils in ambient air was conducted at temperatures ranging from $704-815^{\circ} \mathrm{C}\left(1300-1500^{\circ} \mathrm{F}\right)$. Figure 4 presents the test results in terms of specific weight change (measured specimen weight divided by surface area) as a function of time.

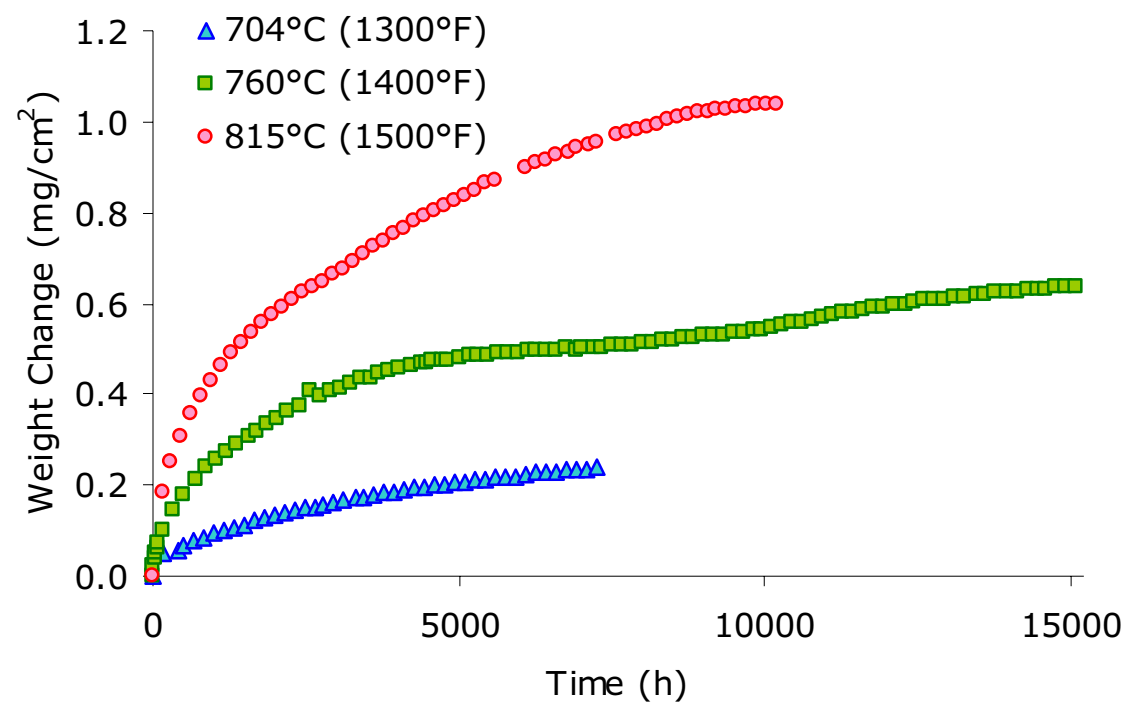

Figure 4: Weight change due to oxidation as a function of time for 625 alloy foil exposed in ambient air.

No evidence of spallation or breakaway oxidation was noted during the ambient air test program. The oxidation kinetics derived from the ambient air exposures are essentially parabolic in nature, as can be seen when the weight change data is plotted as a function of the square root of time (Figure 5). Minor, short-term deviations are present in the kinetics, particularly at $760^{\circ} \mathrm{C}$, over the course of 15,000 total hours at temperature extended over two years of testing. These were traced back primarily to minor temperature fluctuations during the course of the extended testing program. Longer-term deviations tended to evolve towards lower than expected weight gains, particularly at $760^{\circ} \mathrm{C}$ and $815^{\circ} \mathrm{C}$. This is possibly due to microstructural and compositional changes in the thin foil substrates during the course of the exposures.

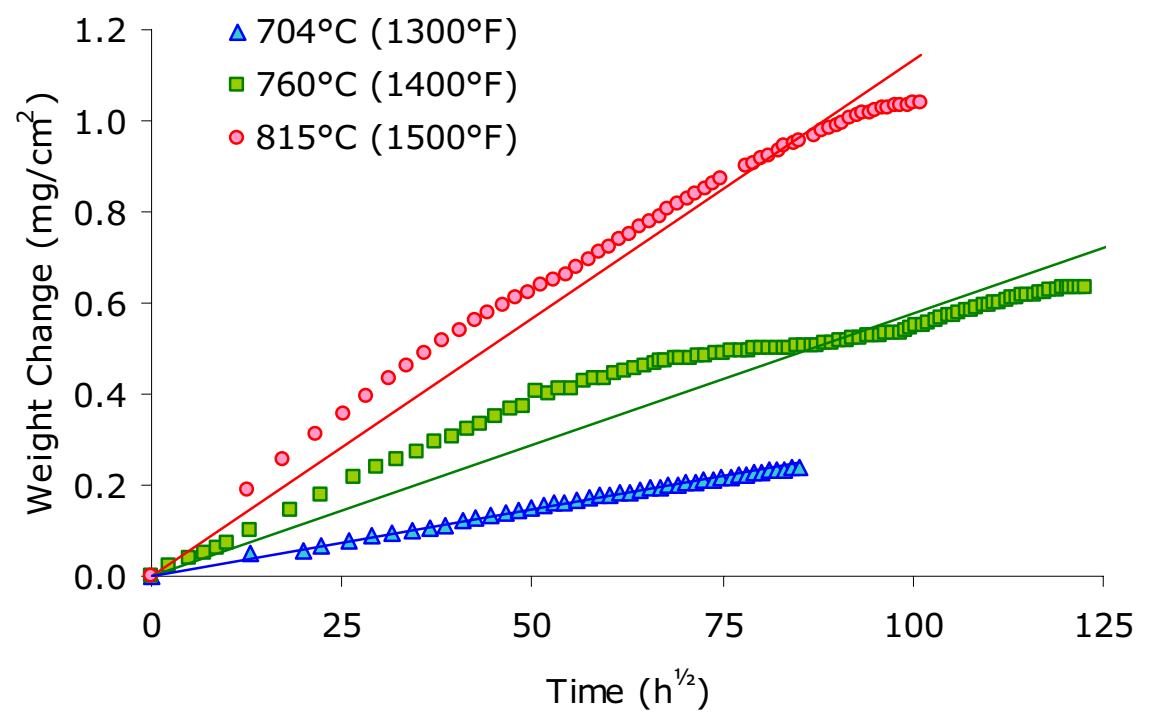

Figure 5: Weight change due to oxidation as a function of the square root of time for 625 alloy foil exposed in ambient air. 
Oxide scales generally grow via diffusion of charged species through the condensed oxide, a process which can be described by the parabolic rate law (Equation 3). In this simple rate law expression, $\Delta W / A$ is specific weight change and $t$ is time. The value $k_{p}$ is the parabolic rate constant.

$$
(\Delta W / A)=k_{p}^{\prime} \cdot \sqrt{t}
$$

The long-term test data, along with that obtained from other shorter-term tests, was evaluated to determine the parabolic rate constant for oxide scale growth (Table II).

Table II. Parabolic rate constants for oxidation of 625 alloy foil in ambient air

\begin{tabular}{cccc}
\hline \multicolumn{2}{c}{ Temperature } & \multicolumn{2}{c}{ Parabolic rate constant $\left(\mathrm{k}_{\mathrm{p}}\right)$} \\
$\left({ }^{\circ} \mathrm{F}\right)$ & $\left({ }^{\circ} \mathrm{C}\right)$ & $\left(\mathrm{g}^{2} / \mathrm{cm}^{4} \mathrm{~h}\right)$ & $\left(\mathrm{g}^{2} / \mathrm{cm}^{4} \mathrm{~s}\right)$ \\
\hline 1175 & 635 & $1.1 \mathrm{E}-13$ & $3.1 \mathrm{E}-17$ \\
1202 & 650 & $2.2 \mathrm{E}-13$ & $6.1 \mathrm{E}-17$ \\
1300 & 704 & $8.1 \mathrm{E}-12$ & $2.3 \mathrm{E}-15$ \\
1337 & 725 & $6.5 \mathrm{E}-12$ & $1.8 \mathrm{E}-15$ \\
1400 & 760 & $3.8 \mathrm{E}-11$ & $1.0 \mathrm{E}-14$ \\
1500 & 815 & $1.4 \mathrm{E}-10$ & $4.0 \mathrm{E}-14$ \\
\hline
\end{tabular}

Oxide growth is a thermally activated, solid-state diffusion-controlled process. The parabolic rate constants therefore obey an Arrhenius relationship. Figure 6 indicates that the activation energy is constant across the temperature and time ranges investigated, suggesting that the mechanism for oxide scale growth is essentially invariant.

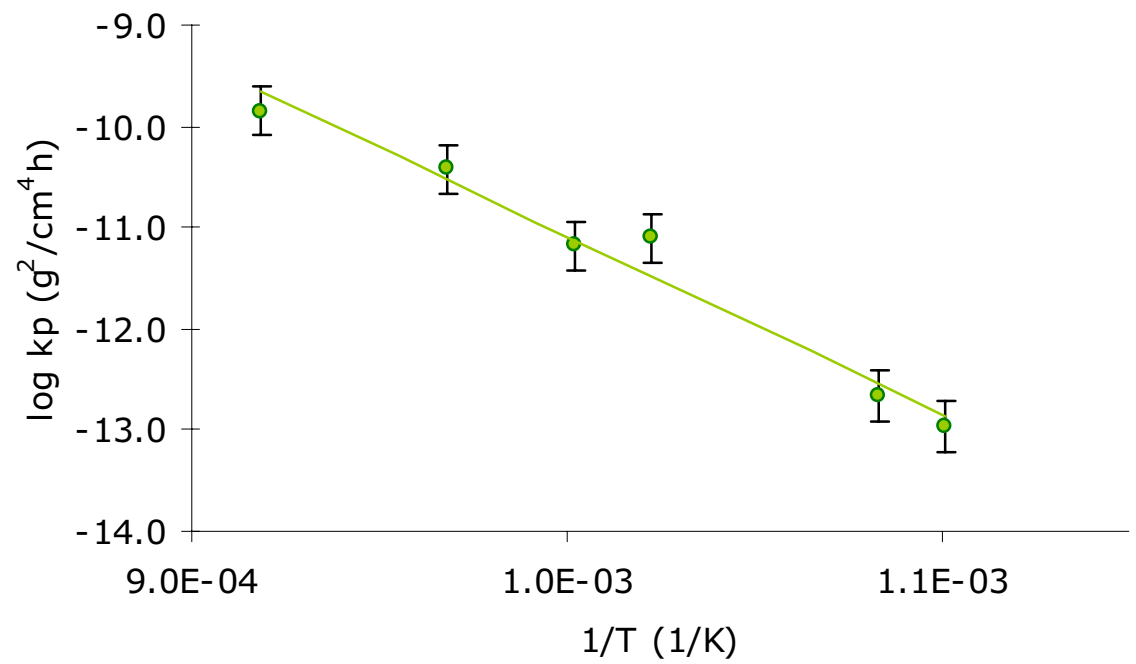

Figure 6: Arrhenius plot of parabolic rate constants for 625 alloy foil exposed in ambient air.

The data in Figure 6 yields an expression for the parabolic rate constant as a function of temperature(Equation 4), valid for temperatures ranging from $908-1088 \mathrm{~K}\left(635-815^{\circ} \mathrm{C}\right)$.

$$
\log k_{p}=-17479(1 / T)+6.4
$$




\section{Oxidation Test Results - Effect of Water Vapor}

Test exposures comparable to those performed in ambient air were carried out for extended periods of time in air containing added water vapor (Figure 7). An overall trend of more rapid oxidation at lower temperatures and shorter times followed by weight loss at higher temperatures and longer test times is apparent, reasonably suggesting that the role of oxide scale evaporation becomes greater at higher temperatures. Evidence of oxide spallation was not noted during periodic visual examinations, leading to the assumption that oxide scale evaporation was responsible for the weight losses.

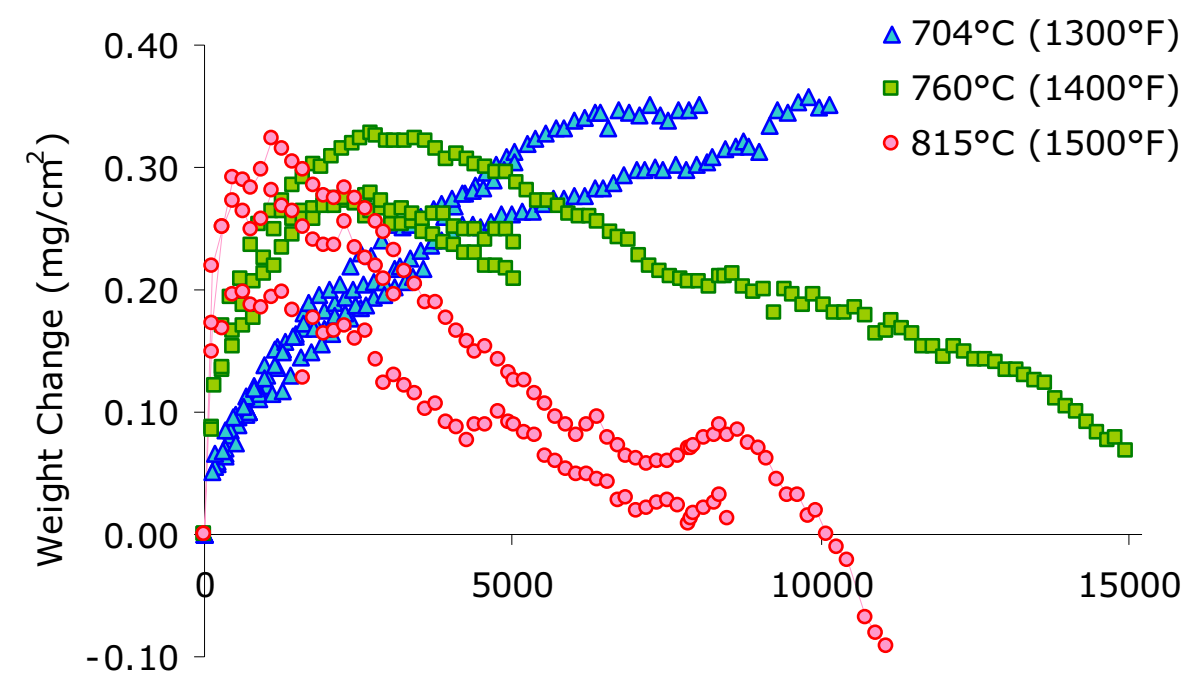

Time (h)

Figure 7: Weight change due to oxidation as a function of time for 625 alloy foil exposed in air containing $7 \%$ water vapor

(multiple samples exposed at each test temperature).

The weight gain, or pre-peak segments of these curves are controlled by diffusional growth kinetics, while the weight loss, or post-peak segments of the oxidation weight change curves are dominated by linear evaporation kinetics. The slopes of the curves in these regions can be measured and used to calculate the apparent parabolic rate constants for growth and the linear rate constants for evaporative weight loss, respectively (Table III). The values so obtained are influenced by the simultaneous growth and thinning of the oxide scale and therefore do not represent exact measurements of these values. It can be noted that the initial segments of the weight change curves obtained during testing in air containing water vapor exhibit parabolic rate constants which are similar to those measured for comparable ambient air exposures (taken from Table II and presented for direct comparison).

Table III. Rate constants for oxidation of 625 alloy foil in air with and without added water vapor

\begin{tabular}{ccccc}
\hline \multicolumn{2}{c}{ Temperature } & \multicolumn{2}{c}{ ambient air } & \multicolumn{2}{c}{ humidified air } \\
$\left({ }^{\circ} \mathrm{F}\right)$ & $\left({ }^{\circ} \mathrm{C}\right)$ & $\log \mathrm{kp}\left(\mathrm{g}^{2} / \mathrm{cm}^{4} \mathrm{~s}\right)$ & $\operatorname{log~kp~}\left(\mathrm{g}^{2} / \mathrm{cm}^{4} \mathrm{~s}\right)$ & $\operatorname{log~kl}\left(\mathrm{g} / \mathrm{cm}^{2} \mathrm{~h}\right)$ \\
\hline 1300 & 704 & -11.1 & -10.7 & - \\
1400 & 760 & -10.4 & -10.9 & -7.7 \\
1500 & 815 & -9.8 & -9.8 & -7.2 \\
\hline
\end{tabular}


As noted previously, oxide scales generally grow via thermally activated diffusion in the solidstate. Evaporation kinetics typically obey a linear rate law. These two processes can be described individually by Equation 5 (a revision of Equation 3) and Equation 6, respectively. In these simple rate law expressions, $x$ refers to oxide thickness, $t$ to time, and $k_{p}$ ' and $k_{l}$ ' are constants (at a given temperature) describing parabolic oxidation (the "scaling constant") and linear evaporation.

$$
\begin{gathered}
x=k_{p}^{\prime} \cdot \sqrt{t} \\
x=k_{l}^{\prime} \cdot t
\end{gathered}
$$

Equations 5 and 6 cannot simply be added when both mechanisms are operative, as the magnitude of diffusional growth will be impacted by oxide scale thinning due to evaporation. The experimentally observed oxidation kinetics can be explained by a model combining the simultaneous growth and evaporation of an oxide layer. Equation 7, after Tedmon, can be used to calculate the overall kinetics in such a situation [38].

$$
\frac{\partial x}{\partial t}=\left(k_{p}^{\prime} / x\right)-k_{l}^{\prime}
$$

Oxygen uptake, controlled by solid-state diffusion through the scale, dominates the initial oxidation kinetics as described by Equation 7. This results in an overall weight gain due to oxide growth. The length of this initial period and the magnitude of the effect strongly depends on the relative values of the two competing rate constants. The rate of growth eventually slows as the oxide scale thickens and evaporation (a surface process which is independent of oxide scale thickness) begins to control the weight change kinetics. Eventually, the sample begins to lose weight. Equation 7 can be integrated (assuming $\mathrm{x}=0$ at $\mathrm{t}=0$ ) to yield equation 8 .

$$
t=\frac{k_{p}^{\prime}}{\left(k_{l}^{\prime}\right)^{2}}\left[-\frac{k_{l}^{\prime}}{k_{p}^{\prime}} x-\ln \left(1-\frac{k_{l}^{\prime}}{k_{p}^{\prime}} x\right)\right]
$$

Equation 8 is amenable to numerical solution, allowing oxide thickness to be calculated at any given time. This can then be converted to the weight of condensed oxide scale per unit area by multiplying by the density of chromium oxide. The overall estimated weight change is then calculated by subtracting the weight loss due to evaporation, obtained in a similar fashion from Equation 6. The observed oxidation test data were found to agree qualitatively with calculations made using this model. Figure 8 presents both experimental weight change data and the calculated weight change curve for a model exposure at $760^{\circ} \mathrm{C}$ in air containing $7 \%$ water vapor. The shape and magnitude of the predicted curve matched reasonably well with the experimental data. The primary variable in the solution to the kinetics equation is the relative uncertainty of the absolute value of the rate constant for linear evaporation, which strongly affects the shape of the predicted weight change curve, and the inflection point where the sample transitions from weight gain to weight loss. The currently-used value was estimated from oxidation test data and is not known with precision. Quantitative predictions require more accurate knowledge of this parameter, which depends on both thermodynamic factors (e.g. temperature, activity of chromium oxide at the scale/gas interface) and kinetic factors (e.g. gas flow rate). 


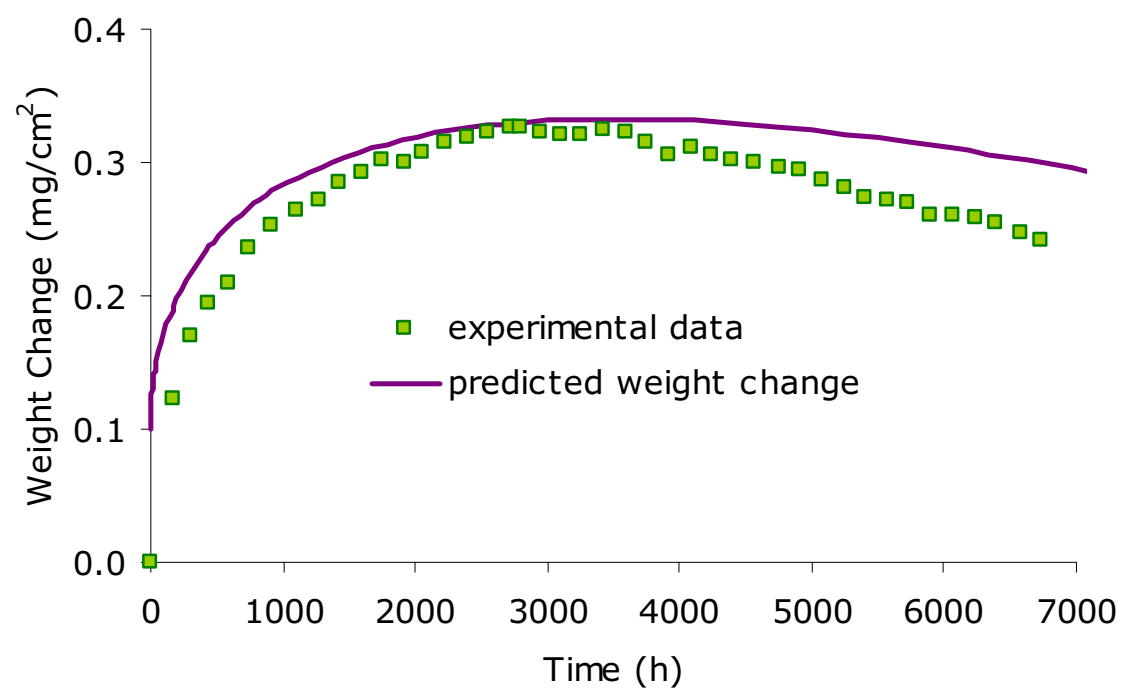

Figure 8: Comparison of experimentally measured and predicted weight change due to oxidation as a function of time for 625 alloy foil exposed at $760^{\circ} \mathrm{C}\left(1400^{\circ} \mathrm{F}\right)$ in air containing $7 \%$ water vapor.

The three long-term weight change curves presented in Figure 7 for oxidation in air containing $7 \%$ water vapor can be directly compared using calculations based on the parabolic rate law. Equation 3 can be used to describe the expected weight gain during parabolic oxidation. Provided that the mechanism controlling the oxidation process does not change, any two exposures " $\mathrm{A}$ " and "B" with unique conditions of time and temperature are equivalent when the oxide scale which forms is identical (i.e. the two oxide scale layers are indistinguishable in terms of thickness, composition, and density) at the end of the two exposures. Equation 9 expresses this concept mathematically in terms of specific weight change.

$$
(\Delta W / A)_{\exp A}^{2}=(\Delta W / A)_{\exp B}^{2}
$$

Equation 9 can be rewritten to yield Equation 10, which takes into account time (directly) and temperature (indirectly, through the parabolic rate constant) by incorporating Equation 3 on both sides of the equation.

$$
k_{p(\exp A)} t_{\exp A}=k_{p(\exp B)} t_{\exp B}
$$

To specifically treat the data obtained from testing 625 foil in humidified air, Equation 4 can be substituted for the rate constant terms in Equation 10. This can be done with some confidence, as the effect of water vapor on the parabolic growth segments of the curves obtained in air containing water vapor was found to be relatively minor. The resulting expression can be solved for time (Equation 11).

$$
t_{\exp B}=\frac{k_{p(\exp A)} t_{\exp A}}{k_{p(\exp B)}}=\frac{\left[10^{\left(-17479\left(1 / T_{A}\right)+6.4\right)}\right] t_{\exp A}}{10^{\left(-17479\left(1 / T_{B}\right)+6.4\right)}}
$$

Equation 11 can be used to transform, data point by data point, a weight change curve obtained during an experiment at a specific temperature $\mathrm{T}_{\mathrm{A}}$ to an equivalent exposure at any arbitrary temperature $T_{B}$, as long as $T_{B}$ is within the bounds set on Equation 4 . 
Figure 9 is a revision of Figure 7, with the weight change data shifted to equivalent exposures at $760^{\circ} \mathrm{C}$. The test data obtained at $760^{\circ} \mathrm{C}$ curve is naturally unaffected, while the curves for the samples exposed at $704^{\circ} \mathrm{C}$ and $815^{\circ} \mathrm{C}$ curves are compressed and expanded to dramatically shorter and longer times, respectively. The peaks in the weight change curves for the two higher temperature exposure curves occur at essentially coincident times when the data is treated in this fashion, suggesting that the rates for growth and evaporation do not greatly diverge over the $55 \mathrm{C}^{\circ}$ test temperature differential.

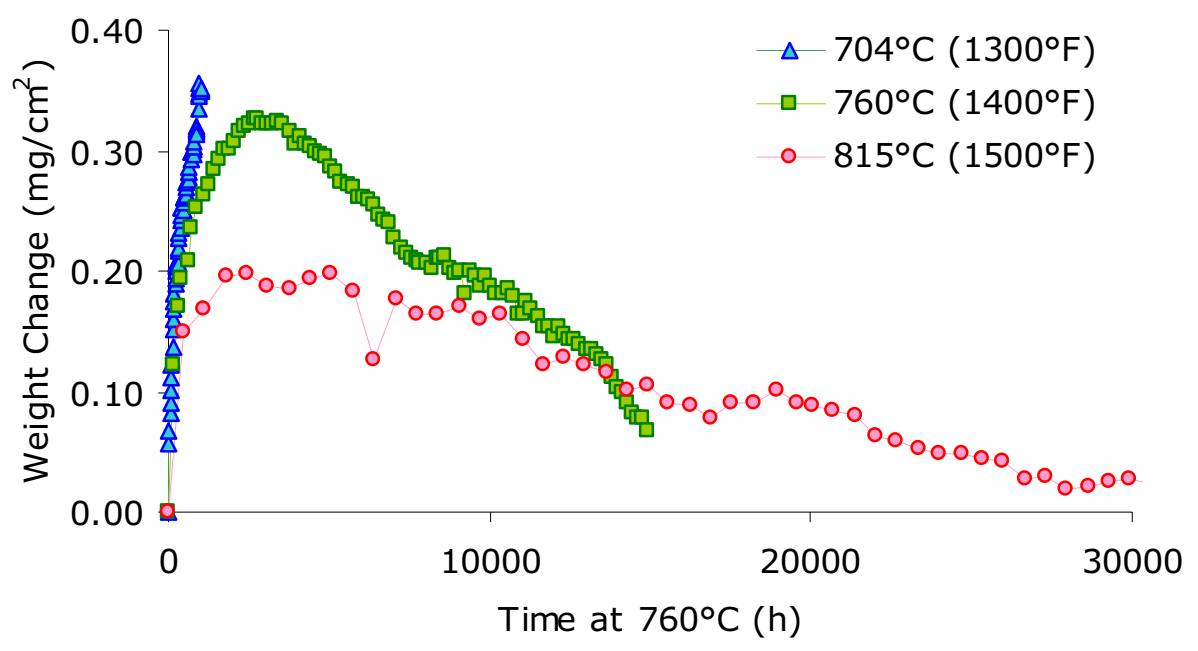

Figure 9: Weight change due to oxidation as a function of time for 625 alloy foil exposed in air containing $7 \%$ water vapor, all curves converted to equivalent time exposures at $760^{\circ} \mathrm{C}\left(1400^{\circ} \mathrm{F}\right)$.

A similar process can be used to predict when the transition to net weight loss will occur at lower temperatures. Figure 10 is a second revision of Figure 7, with the weight change data shifted in this case to equivalent exposures at $704^{\circ} \mathrm{C}$. This time the actual $704^{\circ} \mathrm{C}$ curve is unaffected, while the $760^{\circ} \mathrm{C}$ and $815^{\circ} \mathrm{C}$ curves are both expanded to longer times. The exponential effect of increasing temperature on the rate of oxidation is significant - the data is necessarily plotted on a semi-log scale for clarity. The peak weight change curve for the two higher temperature exposure curves are again coincident and predict that net weight loss will not be observed until approximately 30,000 hours of exposure at $704^{\circ} \mathrm{C}$.

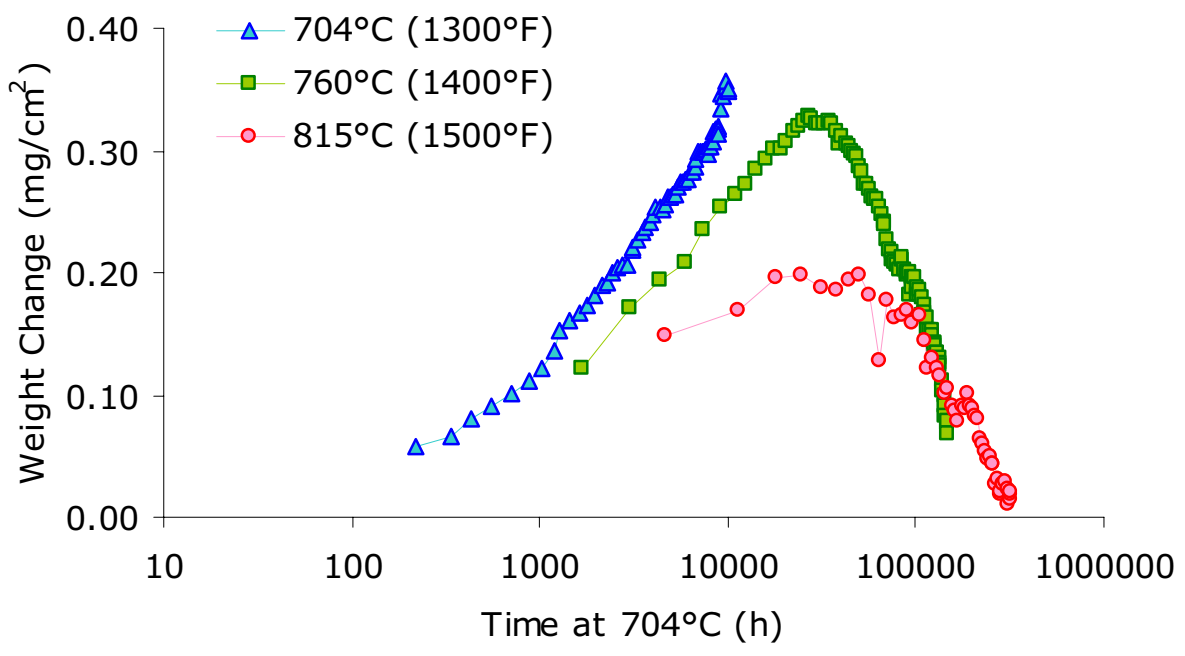

Figure 10: Weight change due to oxidation as a function of time for 625 alloy foil exposed in air containing 7\% water vapor, all curves converted to equivalent time exposures at $704^{\circ} \mathrm{C}\left(1300^{\circ} \mathrm{F}\right)$. 


\section{Effect of Minor Alloying Additions on Reducing Oxide Scale Evaporation}

The magnitude of chromium oxide scale evaporation can be mitigated to an extent by adding elements which reduce the chromium content in the outer regions of the surface oxide layer. Manganese has been found to be efficient in this regard, as it exhibits relatively high mobility and low solubility in chromium oxide [39]. This results in rapid migration of manganese to the scale/gas interface, where it forms a manganese chromate spinel layer $\left(\mathrm{MnCr}_{2} \mathrm{O}_{4}\right)$. The spinel effectively reduces the activity of chromium oxide in contact with the atmosphere, which in turn causes the partial pressure of chromium-bearing vapor species to decrease. An example of the effect of manganese additions on oxide scale evaporation is presented in Figure 11, which compares the oxidation weight change curves for 625 alloy $(0.03 \% \mathrm{Mn}), \mathrm{HX}$ alloy $(0.6 \% \mathrm{Mn})$ and AL $20-25+\mathrm{Nb}$ austenitic stainless steel (1.0\% Mn).

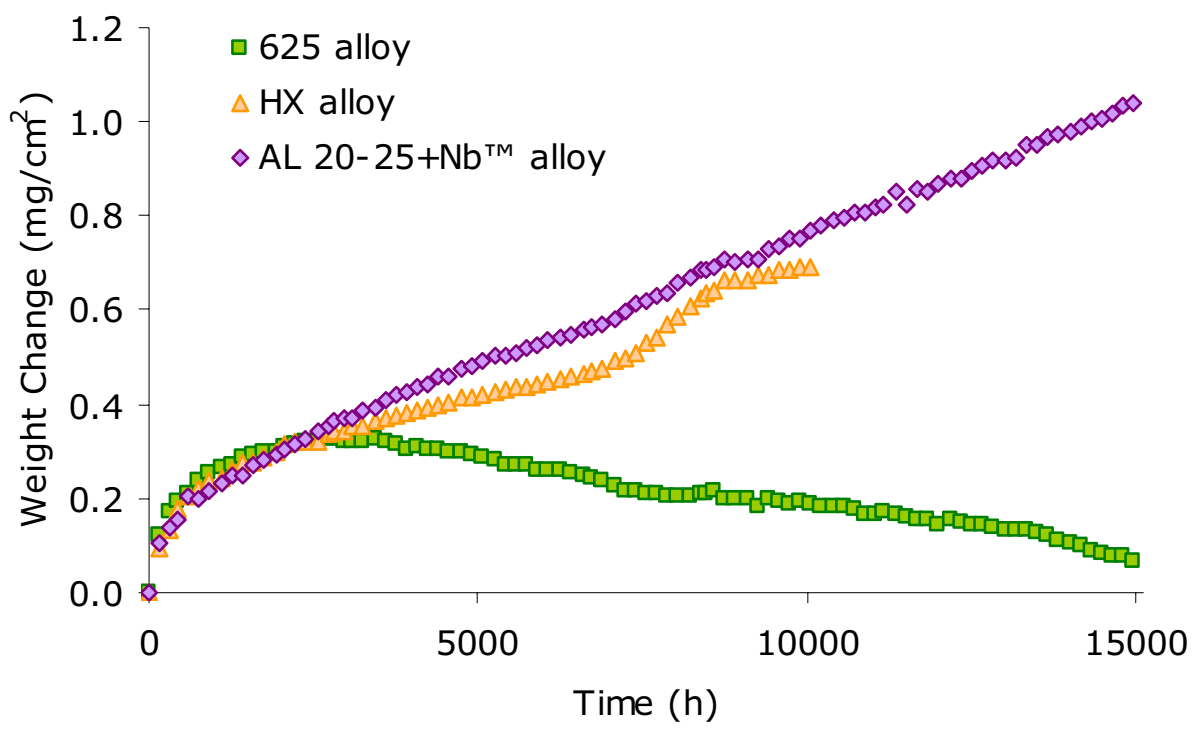

Figure 11: Weight change due to oxidation as a function of time for three different alloys exposed at $760^{\circ} \mathrm{C}\left(1400^{\circ} \mathrm{F}\right)$ in air containing $7 \%$ water vapor.

A detailed analysis of the oxide scale confirms the role of manganese on reducing chromium volatility. A scanning electron microscope (SEM) equipped with X-ray energy dispersive analysis (XEDS) capabilities was used to quantitatively determine the compositions of the oxide scales formed on the two alloys during high temperature exposures to air containing water vapor as a function of position within the scale. All measurements were performed using a Philips XL30 FEG SEM. The amount of each oxide was quantified by the instrument's analytical software by measuring the peak intensities for the metallic elements and assuming that oxides of a given stoichiometry are present. The oxide scale formed on the 625 alloy samples was found to be essentially pure chromium oxide, to the practical detection limit of the instrument (i.e. the oxide was nominally $99 \% \mathrm{Cr}_{2} \mathrm{O}_{3}$ ). Significant segregation of manganese to the scale/gas interface was detected for the HX and AL $20-25+\mathrm{Nb}$ alloy samples. Figure 12 is a plot of $\mathrm{MnO}: \mathrm{Cr}_{2} \mathrm{O}_{3}$ ratio across the thickness of the oxide formed on the $\mathrm{HX}$ alloy sample exposed for 10,000 hours at $760^{\circ} \mathrm{C}\left(1400^{\circ} \mathrm{F}\right)$ in air containing $7 \%$ water vapor. The manganese content adjacent to the scale/alloy interface was low, and then increased abruptly to a 1:1 ratio near the scale/gas interface. This indicates that the oxide scale consists of an inner layer of chromium oxide and an outer layer of manganese-saturated $\mathrm{MnCr}_{2} \mathrm{O}_{4}$ spinel. 


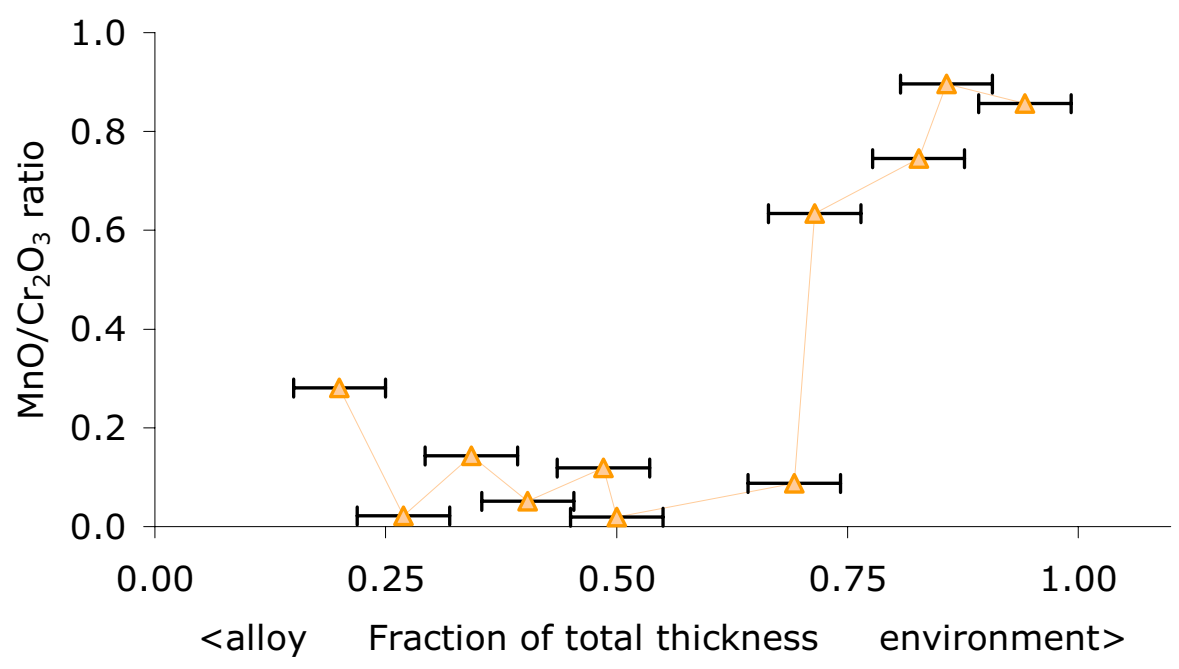

Figure 12: Molar ratio of $\mathrm{MnO}$ to $\mathrm{Cr}_{2} \mathrm{O}_{3}$ as a function of distance from the scale/metal interface for a $\mathrm{HX}$ alloy sample exposed at $760^{\circ} \mathrm{C}\left(1400^{\circ} \mathrm{F}\right)$ in air containing $7 \%$ water vapor for 10,000 hours.

It should be noted that recent studies reported in the literature have found that manganese additions may be less effective for exposures under more severe conditions, e.g. higher temperatures, higher water vapor levels, and longer times) [34].

\section{Effect of Oxide Scale Evaporation on Chromium Depletion During Oxidation}

A metallic alloy substrate will irreversibly lose chromium during high temperature oxidation due to its incorporation into the oxide scale. Oxide scale evaporation should serve to increase this depletion via the formation and loss of chromium-bearing volatile species. Chromium depletion gradients were determined for selected post-test specimens polished in cross-section using a SEM equipped with an X-Ray energy dispersive spectrometer (XEDS). The spectra were taken with a rapidly-scanning line probe to yield the average chromium content at a fixed distance from the interface between the oxide and substrate. This was done to eliminate local variability in chromium content caused by the formation of small second-phase particles while maintaining the best possible spatial resolution in terms of depth measurement. A standards-based routine was used to improve the accuracy of the analysis. The standard used was a section of unexposed, single-phase 625 alloy foil from the same lot as the test specimens.

Exposing samples in humidified air resulted in significantly increased chromium loss. The maximum depletion level after 10,000 hours at $704^{\circ} \mathrm{C}$ is to approximately ten weight percent in both $7 \%$ and $10 \%$ water vapor, to a total depth of about twenty to thirty microns. This compares to a maximum depletion level of about fifteen weight percent and a total depth of about ten microns in ambient air. (Figure 13) Note that the effects of chromium volatility at $704^{\circ} \mathrm{C}$ can be clearly observed in the substrate while not being manifested as a tendency towards overall weight loss in the oxidation kinetics, at least for the time and temperature used for this test. 


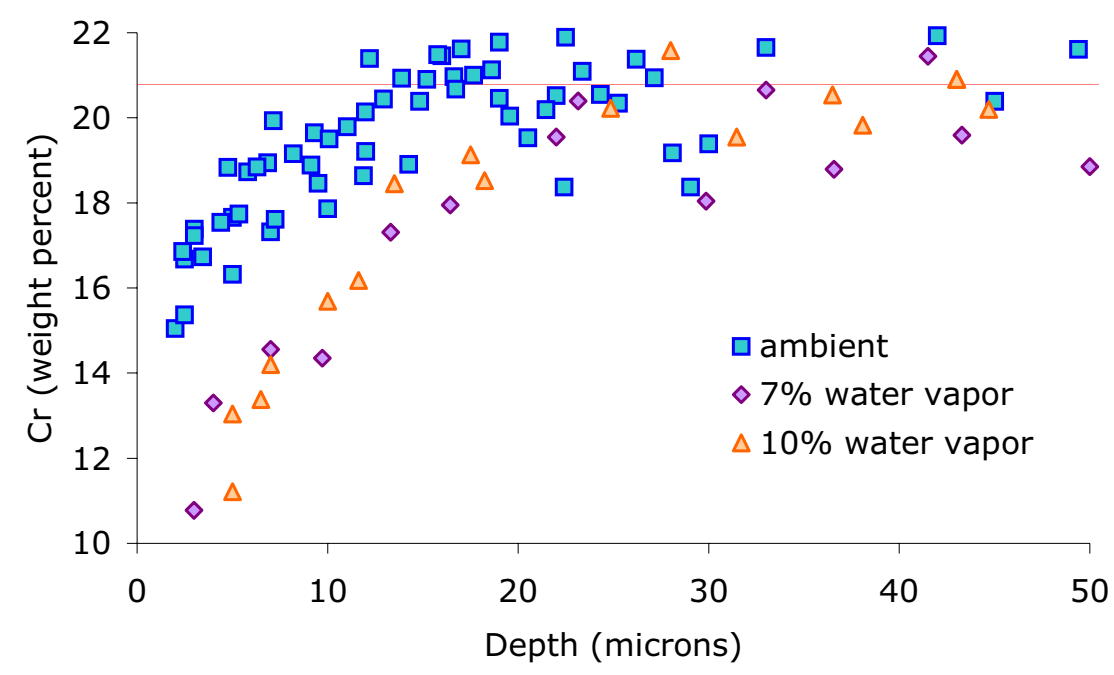

Figure 13: Effect of water vapor on the residual chromium content of 625 alloy substrates exposed at $704^{\circ} \mathrm{C}\left(1300^{\circ} \mathrm{F}\right)$ in air containing $7 \%$ water vapor for 10,000 hours.

Chromium depletion again was found to be significantly greater in the presence of water vapor at $760^{\circ} \mathrm{C}$ (Figure 14). The maximum absolute chromium depletion level measured for a sample exposed in air containing 7\% water vapor for 8,000 hours was approximately twelve weight percent, which is not as low as was noted at $704^{\circ} \mathrm{C}$ (note that no direct comparison in terms of time was available for this specific test condition). However, at this temperature, the effect of chromium depletion reached essentially to the sample centerline, suggesting that the higher temperature promoted diffusion of chromium from the center of the sample to the surface.

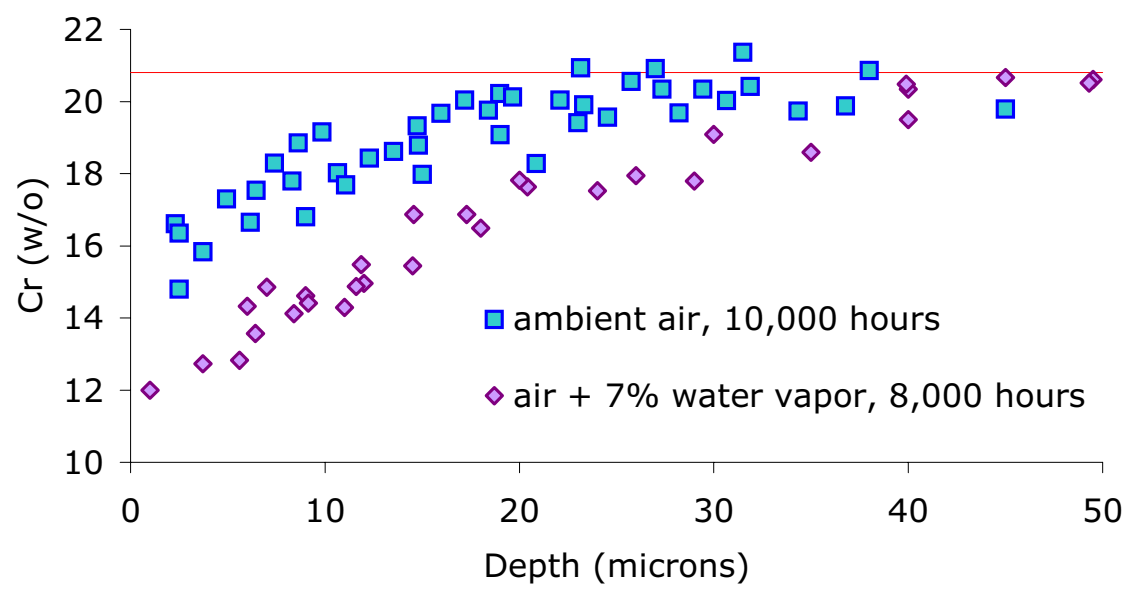

Figure 14: Effect of water vapor on the residual chromium content of 625 alloy substrates exposed at $760^{\circ} \mathrm{C}\left(1400^{\circ} \mathrm{F}\right)$ in air containing $7 \%$ water vapor.

An estimation was made of the average chromium left in the foil, independent of thickness, by measuring the area under the chromium compositional profiles after exposures of 5,000 and 10,000 hours (nominal) in both ambient and humidified air (Table IV). The effect of water vapor was clearly to enhance the amount of chromium lost over that noted for ambient air exposures. 
Table IV. Average residual chromium content after exposure, estimated from area under chromium profile curves (weight percent)

\begin{tabular}{rcc}
\hline & 5,000 hours & 10,000 hours \\
\hline $704^{\circ} \mathrm{C}\left(1300^{\circ} \mathrm{F}\right)$ & & \\
ambient air & 20.0 & 19.7 \\
air $+7 \%$ water vapor & 19.2 & 18.1 \\
air $+10 \%$ water vapor & 19.2 & 17.9 \\
\hline $760^{\circ} \mathrm{C}\left(1400^{\circ} \mathrm{F}\right)$ & & \\
ambient air & 18.5 & 18.5 \\
air $+7 \%$ water vapor & 17.0 & $16.0^{*}$ \\
\hline initial chromium content & & 20.4 \\
\hline
\end{tabular}

* actual exposure was 7,992 hours

\section{Conclusions}

Heat-resistant materials such as 625 alloy which rely on the formation of chromium oxide for protection against high-temperature oxidation can be susceptible to chromium loss via the formation of volatile species in the presence of water vapor. The observed oxidation kinetics can be described by a model based on the simultaneous diffusional growth and linear evaporation of an oxide scale. A detailed evaluation of the oxidation kinetics suggests that a similar growthevaporation mechanism is operative across the temperature range examined. Microstructural evidence suggests that the low manganese content of the 625 alloy foil used for this study may play a significant role in enhancing chromium evaporation.

Microprobe measurements of chromium depletion profiles in the substrate revealed that the 625 alloy foil samples exposed to humidified air exhibit lower residual chromium levels, even for exposures performed at lower temperatures where the effect of evaporation was not notable in the oxidation weight change kinetics. Excessive chromium depletion can lead to the formation of rapidly-growing oxides, i.e. accelerated or breakaway oxidation. None of the 625 alloy samples exposed to humidified air exhibited a tendency towards breakaway oxidation, even during severe exposures which resulted in high chromium depletion levels. This suggests that 625 alloy is resistant to this form of degradation.

\section{Acknowledgements}

This work was funded in part by the Department of Energy Contract \#DE-FC02-00CH11062, administered by Solar Turbines Incorporated. 


\section{References}

1. Kubaschewski, O. and B.E Hopkins. Oxidation of Metals and Alloys. London: Butterworths, 1962.

2. Caplan, D. and M. Cohen. Corrosion 15 (1959): p. 57-62.

3. Fujii, C.T. and R.A. Meussner. J. Electrochem. Soc. 110 (1963): p. 1195-1204.

4. Fujii, C.T. and R.A. Meussner. J. Electrochem. Soc. 111 (1964) p. 1215-1221.

5. Wood, G.C. et al. Werk. Korr. 8, (1970): p. 900-910.

6. Graham H. C. and H.H. Davis. J. Am. Cer. Soc. 54.2 (1971): p. 89-93.

7. Kvernes, I. et al. Corr. Sci. 17 (1977): p. 237-252.

8. Kofstad, P. High Temperature Corrosion. London: Elsevier, 1988.

9. Khanna, A.S. and P. Kofstad. Proceedings of the International Conference Held at the University of Cambridge, March 26-28, 1990. ed. M. J. Bennett and G. Lorimer. London: IOM, 1991.

10. Chaudanson, H. et al. Proceedings of Eurocorr '91 Budapest, October 21-25, 1991. ed. I. Karl and M. Bod. European Federation of Corrosion Budapest, Hungary, 1991.

11. Saeki, I. et al. Corr. Sci. 38, 1 (1995): p. 19-31.

12 Jianian, S. et al. Oxid. Met. 48, 3/4 (1997): p. 347-357.

13. Saeki, I. et al. Corr. Sci. 40, 2/3 (1998): p. 191-200.

14. Lee, Y. et al. Proceedings of the Third International Conference on the Microscopy of Oxidation Held at Trinity Hall the University of Cambridge, September 16-18 1996. ed. S. B. Newcomb and J. A. Little. London: IOM, 1996.

15. Ozturk, B. and R. Matway. ISIJ Int. 37.2 (1997): p. 169-197.

16. Asteman, H. et al. Oxid. Met. 52, (1999): p. 95-111.

17. Asteman, H. et al. Oxid. Met. 54, (2000): p. 11-26.

18. Pint, B. A. and J. M. Rakowski. "Paper 00259 Effect Of Water Vapor On The Oxidation Resistance Of Stainless Steels." Proceedings of NACE/2000, Orlando FL, March 26-31 2000. Houston: NACE International, 2000.

19. Rakowski, J. M. and B. A. Pint. "Paper 00517 Observations Of The Effect Of Water Vapor On The Elevated Temperature Oxidation Of Austenitic Stainless Steel Foil." Proceedings of NACE/2000, Orlando FL, March 26-31 2000. Houston: NACE International, 2000.

20. Rakowski, J. M. "Paper 2001-GT-0360 The Oxidation of Austenitic Stainless Steel Foil in Humidified Air." Proceedings of the ASME IGTI Turbo Expo, New Orleans LA, June 4-7 2001. New York: ASME International, 2001.

21. Kofstad, P. High Temperature Oxidation of Metals. New York: John Wiley and Sons, 1966.

22. Meier, G. H. and N. Birks. Introduction to High Temperature Oxidation of Metals. London: Edward Arnold, 1983.

23. Ebbinghaus, B.B. Combustion and Flame 93 (1993): p. 119-137.

24. Asteman, H. et al. Oxid. Met. 57 (2002): p. 193-216.

25. Asteman, H. et al. Corr. Sci. 44 (2002): p. 2635-2649.

26. Amy, S. and P. Vangeli. Eurocorr 2001 Congress Proceedings, Lake Garda, Italy, September 30-October 1, 2001. Milano, Italy: Associazione Italiana diMetallurgia, 2001. 
27. Rakowski, J. M. "Paper GT2003-38059 The Oxidation of Metal Alloy Foils in the Presence of Water Vapor." Proceedings of the ASME IGTI Turbo Expo, Atlanta GA, June 16-19 2003. New York: ASME International, 2003.

28. Rakowski, J. M. and D. S. Bergstrom. "The Oxidation of Metal Alloy Foils in the Presence of Water Vapor." (Paper presented at ASM Materials Solutions 2003, Pittsburgh PA. October 15, 2003).

29. Pint, B. A. and R. Peraldi. "Paper GT2003-38692 Factors Affecting Corrosion Resistance of Recuperator Alloys." Proceedings of the ASME IGTI Turbo Expo, Atlanta GA, June 16-19 2003. New York: ASME International, 2003.

30. Douglass, D. L. et al. Oxid Met. 45 5/6 (1996): p. 529-620.

31. Pint, B. A. and R. Peraldi. Oxid Met. 61 5/6 (2004): p. 463-483.

32. Asteman, H. et. al. J. Electrochem. Soc. 1513 (2004): p. 141-150.

33. Rakowski, J. M. et. al. "Paper GT2004-53917 The Use And Performance Of Oxidation And Creep-Resistant Stainless Steels In An Exhaust Gas Primary Surface Recuperator Application." Proceedings of the ASME IGTI Turbo Expo, Vienna, Austria, June 14-17 2004. New York: ASME International, 2004.

34. Pint, B. A. "Paper GT2005-68495 The Effect Of Water Vapor On Cr Depletion In Advanced Recuperator Alloys" Proceedings of the ASME IGTI Turbo Expo, Reno NV, June 69, 2005. New York: ASME International, 2005.

35. Stinner, C. P. and J. M. Rakowski "New Developments in Heat-Resistant Austenitic Stainless Steels." (Paper presented at the USC Steam Boiler Steering Committee Meeting, Columbus, OH, August 4, 2004).

36. Rakowski, J. M. and C. P. Stinner. "Paper 05447 The Use and Performance of Wrought 625 Alloy in Primary Surface Recuperators for Gas Turbine Engines." Proceedings of NACE/2005, Houston TX, April 4-7, 2005. Houston: NACE International, 2005.

37. Visco, S. J. et. al. "Development of Novel Electrode Structures and Stabilization of Metal Components for Cost-Competitive SOFCs." (Paper presented at the Sixth Annual SECA Workshop, Asilomar CA, April 17-21, 2005).

38. Tedmon, C. S. J. Electrochem. Soc. 113 (1966): p. 766-768.

39. Cox, M. G. et al. Phil Mag. 26 (1972): p. 839. 